\title{
NATURAL HISTORY OF THE SPIDER HYPOCHILUS THORELLI MARX (HYPOCHILIDAE) ${ }^{1}$
}

\author{
By Ian C. Fergusson \\ Department of Biology, \\ Western Carolina University, Cullowhee, N. C. ${ }^{2}$
}

\section{INTRODUCTION}

Hypochilus is regarded as the most primitive of the three "hypochilomorph" spider families: the Hypochilidae, Austrochilidae (= Thaididae) and Hickmaniidae (Marples, 1968). These small, closely related families exhibit character states resembling both those of the primitive mygalomorph spiders (suborder Orthognatha) and the araneomorph spiders (suborder Labidognatha). They are considered to be the most primitive araneomorphs (Gertsch, 1958; Marples, 1968). The hypochilomorph families are geographic as well as phylogenetic relicts, being represented by limited populations in such widely-separated areas as the United States (Hypochilidae), China (Hypochilidae), Chile (Austrochilidae), and Tasmania (Hickmaniidae). Clearly, a better understanding of spider evolution may be gained from studies of hypochilomorph biology (Marples, 1968; Shear, I970).

The four known species of Hypochilus occur only in the United States. All are allopatric and are found only in mountainous regions.

Most works on Hypochilus have used only morphological characters to determine the relationships of the Hypochilidae to other spider families. Though mention has been made of web structure (Comstock, 1940; Gertsch, 1958; Hoffman, 1963), only two investigators (Kraus, 1965, and Shear, 1970, with Hypochilus gertschi) have published additional behavioral data. Life history data on $H y$ pochilus are virtually non-existent.

The present study was undertaken to obtain information on the natural history (ecology, life history, and behavior) of Hypochilus thorelli. It is hoped that these data will contribute to an understanding of the evolutionary history of Hypochilus and the Hypo-

\footnotetext{
${ }^{1}$ From a thesis presented to the graduate faculty of Western Carolina University in partial fulfillment of the requirements for the degree of Master of Arts in Biology.

${ }^{2}$ Present address: 524 Benton Street, Missoula, Montana 59801

Manuscript received by the editor October 15, 1972
} 
chilidae, and, in addition, help explain the success (abundance) of this relict species.

\section{METHODS}

Most of the results reported here are based on field observations made from July 1970 to June I97I. For some behavioral observations, spiders were kept in cardboard boxes in a humid basement room. The open sides of the boxes were covered with transparent plastic wrap. A headlamp covered with a red plastic "filter" was used for observing behavior at night.

I collected $H$. thorelli in the following localities in North Carolina: Buncombe County $-3 \mathrm{mi} \mathrm{S}$ of Dillingham, Pisgah National Forest (females). Graham County - Joyce Kilmer Memorial Forest (egg cases). Haywood County - Sherwood Wildlife Management Area, $13 \mathrm{mi} \mathrm{SE}$ of Waynesville (immatures). Jackson County - Cullowhee Mountain, $8 \mathrm{mi} \mathrm{S}$ of Cullowhee (immatures, egg cases); Highway I07, $2 \mathrm{mi} \mathrm{N}$ of Glenville (immatures, egg cases); Little Mill Creek, $5 \mathrm{mi} \mathrm{S}$ of Tuckaseigee (males, females); Mull Creek, Caney Fork Game Area (males, females, immatures, egg cases); Tanassee Creek Reservoir, I2.5 mi SE of Cullowhee (immatures); Wayehutta Creek, 2 mi NE of Cullowhee (male, egg cases); Whitewater Falls, $8 \mathrm{mi} \mathrm{E}$ of Highlands (immatures, egg cases); Wolf Creek, $5 \mathrm{mi} \mathrm{S}$ of Cullowhee (males, females, immatures, egg cases). Macon County - Dry Falls and Cullasaja River gorge, $3 \mathrm{mi} \mathrm{NW}$ of Highlands (males, females, immatures, egg cases). Swain County - Clingman's Dome, Great Smoky Mountains National Park (male); Kephart Prong Trail, GSMNP (egg cases) ; Nantahala Gorge, I 2 mi SW of Bryson City (females, egg cases). Yancey County - "Lost Cove", $30 \mathrm{mi} \mathrm{NE}$ of Asheville (egg cases). H. thorelli was also observed but not collected in Cherokee and Henderson counties, North Carolina and in Blount and Sevier counties, Tennessee. J. Dan Pittillo collected a mature male at Yonah Mountain, White County, Georgia.

Repeated observations were made in the following localities where large populations of $H$. thorelli were located: in Jackson County at Mull Creek, elev. $975 \mathrm{~m}$ (3200 ft), and Wolf Creek, elev. $730 \mathrm{~m}$ $(2400 \mathrm{ft})$; and in Macon County at Dry Falls, elev. I000 m $(3300 \mathrm{ft})$.

Geographic Distribution

Natural History

Hypochilus thorelli occurs at elevations of about $300 \mathrm{~m}$ ( $1000 \mathrm{ft}$ ) 
and above in the Appalachian Mountains of North Carolina, Tennessee, Georgia, and Alabama, and in the Cumberland Plateau of Tennessee and Kentucky. Kaston (1948) reported that Petrunkevitch introduced $H$. thorelli into Meshomasic State Forest in Connecticut in 1932, and that they were "holding their own" in 1937.

Petrunkevitch (1932) gave the Appalachian distribution as a triangle with apices at Blowing Rock, North Carolina, Tallulah Falls, Georgia, and Maryville, Tennessee. The line from Tallulah Falls northwest to Maryville has been extended farther into Georgia and Alabama. The Appalachian populations are separated from the Cumberland populations by the broad valley of the Tennessee River. While the distribution of $H$. thorelli in the Appalachians is apparently limited to the east, south, and west by low elevations, no such geographic barrier is apparent that would limit its northward distribution, or the southward distribution of $H$. gertschi, known from West Virginia and northwestern Virginia. Yet Petrunkevitch (1932) and Hoffman (1963) searched in favorable habitats in the "isthmus" of western Virginia, and were unable to find any populations.

\section{Habitat}

The optimum habitat for $H$. thorelli in North Carolina is in stream gorges in humid deciduous forests at elevations of 600 to $1100 \mathrm{~m}$ $(2000$ to $3600 \mathrm{ft}$ ). Webs are built predominantly on sheltered rock ledges. The undersurfaces of stream bridges and logs overhanging or close to stream banks are also occasionally inhabited.

The availability of web substrate is a factor which limits local distribution. Stable overhanging or vertical surfaces with a number of projections or nearby plants for guy line attachment are necessary.

Humidity is apparently the most important factor limiting local distribution. H. thorelli webs are more abundant close to a stream than farther away. Well-shaded ledges are more likely to be inhabited than poorly-shaded ones. Where the ledges are well-shacied, the webs are built at any place providing good attachment points. On poorlyshaded ledges webs are built close to the ground, usually behind low vegetation where increased shade and plant transpiration keep the humidity higher.

Marginal habitats located included an unshaded roadside ledge $100 \mathrm{~m}$ across cleared land from the nearest stream (Graham County) and a ledge in dense spruce-fir forest on the side of Clingman's Dome at an elevation of $189 \mathrm{I} \mathrm{m}(6200 \mathrm{ft})$.

Hypochilus was observed from 397 to I89 I m ( 1300 to $6200 \mathrm{ft}$ ), but is rare above $1370 \mathrm{~m}(4500 \mathrm{ft})$. 


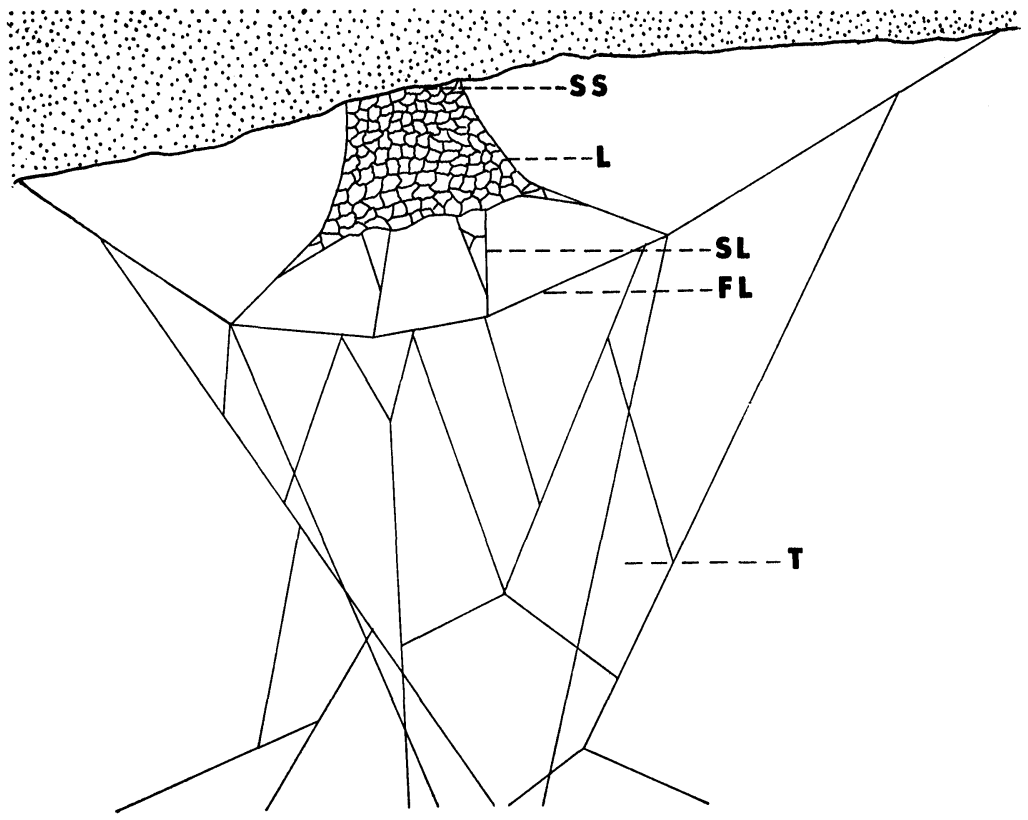

Figure 1. Generalized web structure of $H$. thorelli. S.S., substrate silk; L., lampshade; S.L., support line; F.L., frame line; T., tangle. Drawn from photos.

The densest population observed was at Mull Creek, Jackson County, where 59 individuals were counted one day in June on a rock ledge approximately $15 \mathrm{~m}$ long and I to $3 \mathrm{~m}$ high.

Petrunkevitch (1932) and Hoffman (1963) noted that $H$. thorelli occurs in noticeably drier situations in the Cumberlands than in the Appalachians. J. Beatty (pers. comm.) says that the Alabama populations of $H$. thorelli occupy moist sites when available, and he does not consider them abundant in drier situations. Perhaps, as he suggests, the Cumberland populations have a wider range of moisture tolerance than do the Appalachian populations. Hoffman (1963) and Shear (1970) noted that $H$. gertschi prefers drier situations than does $H$. thorelli, even though moist sites are available.

\section{Prey Capture}

Web construction. The web of Hypochilus is usually described (Comstock, 1940; Gertsch, 1958; Shear, 1970) as a "lampshadeshaped" mesh. The narrower inner end of the lampshade is at- 
tached to a circular sheet of silk laid down on the substrate. The sides of the lampshade extend away from the substrate, flaring to a larger mouth. An extensive tangle of lines connects the lampshade to the surrounding substrate and scrves to keep the lampshade taut. Sticky silk is found only in the lampshade and support lines (Shear, 1970).

The web of $H$. thorelli (Figures I-3) is similar to that of $H$. gertschi, as described by Shear (1970). This includes (following Shear's terminology)) the meshed lampshade, with IO-I5 paired support lines attaching it to a frame line, which is guyed to the substrate and to the extensive angle of threads below the lampshade. $H$. thorelli rests with its ventral surface appressed to the substrate, with all legs touching the lampshade at its base (Figure 4). This is somewhat different from the position of $H$. gertschi, which holds on to the lampshade with its first two pairs of legs, and to the circular sheet with its last two pairs (Shear, I970).

I measured lampshade base diameter, mouth diameter, and depth of io $H$. thorelli webs. The range of values obtained was: base diameter 2.2-7.4 cm, mouth diameter 3.3-I $4.2 \mathrm{~cm}$, depth $\mathrm{I} .5-9.5$ $\mathrm{cm}$. I also measured base diameter of 134 webs in an attempt to determine age classes (see Life History below).

Comstock (1940) observed web construction behavior in $H$. thorelli. He found that the disc of silk was first laid down on the substrate, then the foundations of the lampshade were constructed, and finally the lampshade itself was completed. The only construction activity $I$ observed was web repair after prey-capture. The spider combs its cribellum silk with the calamistra on the last pair of legs, while applying silk to the damaged area. The edges of the torn area of the lampshade are pulled together with the other legs during this process. The spider often returns to the web base, pulls on the sides of the lampshade to test its tension, and then resumes work if the repair is not "satisfactory." Extensive web repair, and probably also web construction, takes place at dusk and night; it was not observed during daylight.

Predatory behavior. H. thorelli does not respond to prey in the tangle below the lampshade unless the impact is violent, in which case it reacts as it does to a threat (see Defensive Behavior). A prey struggling in the sticky lampshade causes the spider to test web tension by flexing its legs and tightening the web in order to locate the prey. (One very large and vigorous insect - an ichneumonid wasp - caused a defensive reaction when it was caught in the lampshade.) The spider than orients so that it faces the prey. Usually 

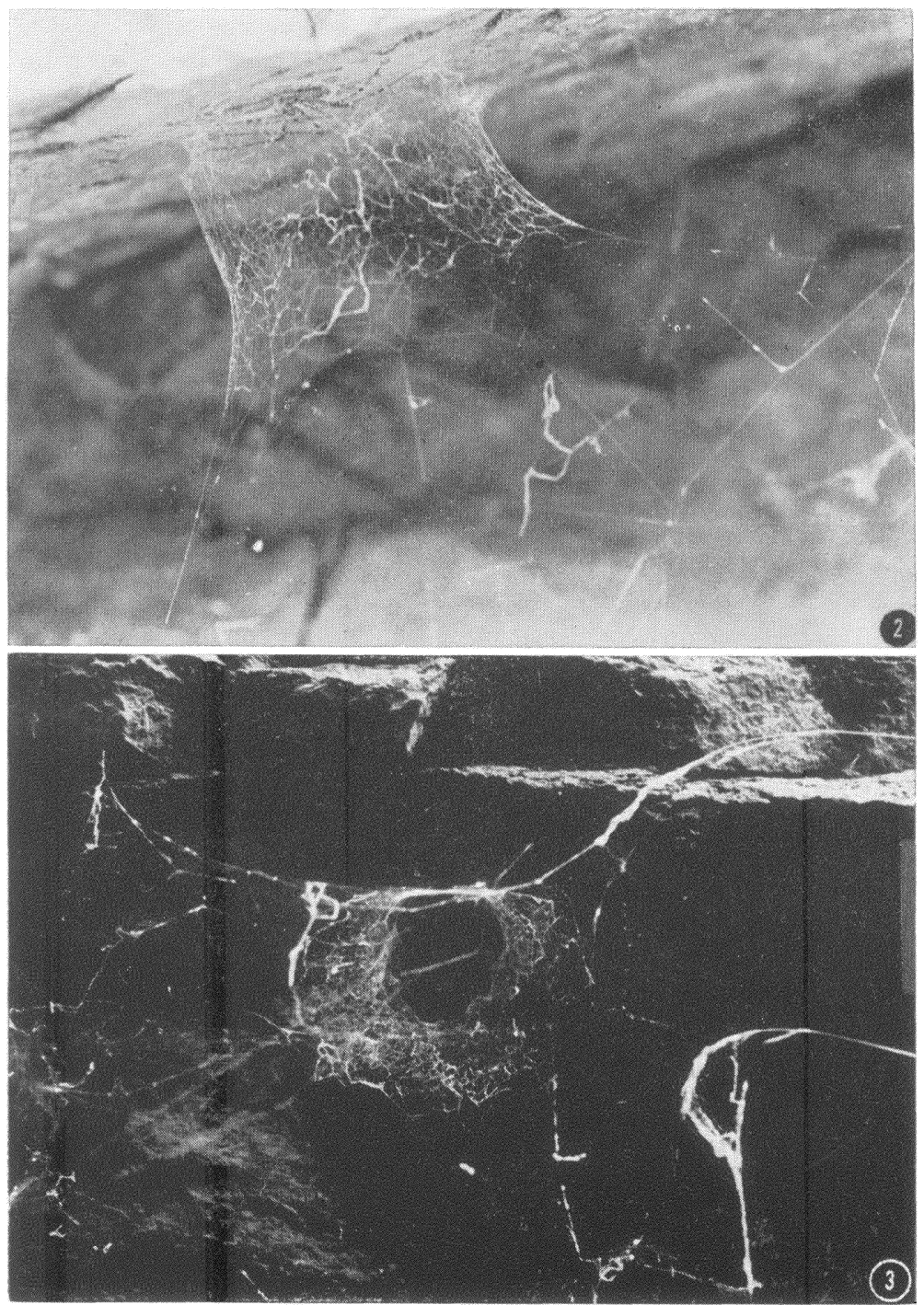

Figure 2. Web of $H$. thorelli, lateral view. Note position of spider against substrate. Photo by L. Tucker.

Figure 3. Web of $H$. thorelli seen from below. Note tangle and flaring of lampshade. The spider is at the center of the web base. 


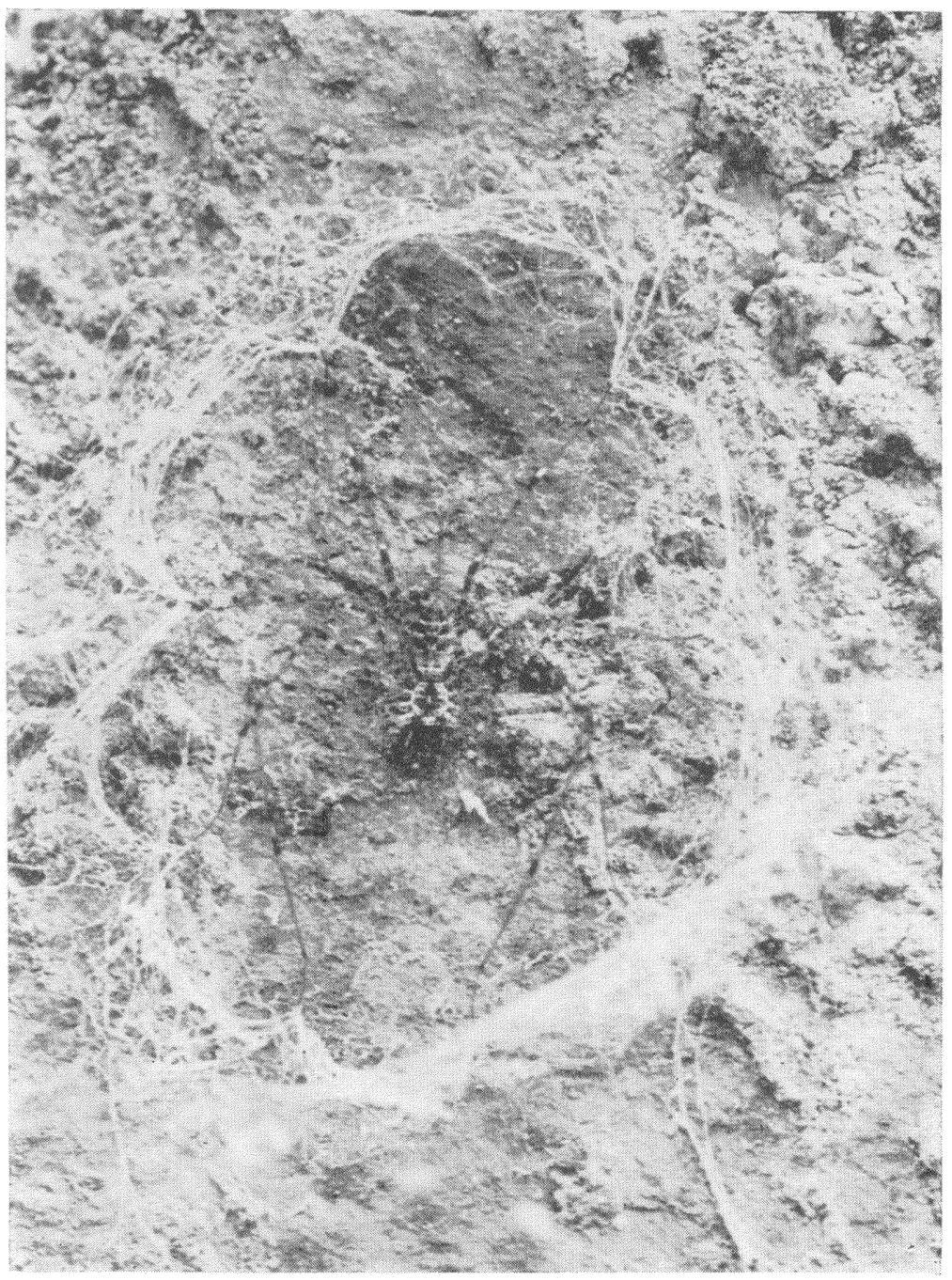

Figure 4. H. thorelli in web. Note cryptic coloration and the legs grasping the lampshade. Photo by L. Tucker. 
it anchors its last pair of legs on the silk base and uses the other legs to grasp the silk near the prey and pull it toward its chelicerae. The struggling of the prey, combined with the pulling of the spider, often thoroughly entangles the prey. When it has pulled the prey close, the spider lunges forward and bites it repeatedly, frequently touching the prey with its pedipalps. Occasionally the spider may lunge at the prey without first pulling on it. It may also bite the prey and hold on for 2-3 minutes before releasing it.

After the prey is dead (2-Io minutes), the spider usually cuts it out of the web with its chelicerae, carries it back to the web base, and assumes its usual resting position. It then feeds, holding the prey only with its chelicerae. After feeding, the spider simply drops the prey remains out of the web.

One prey, an immature Homoptera, was rejected after being killed. The spider cut it out of the web and allowed it to drop out.

On no occasion did I observe $H$. thorelli wrap prey or otherwise use silk to subdue prey, though I did observe one peculiar use of silk. A Hypochilus attacked and killed a small gnaphosid spider, then cut it out of the web. It placed the smaller spider against its spinnerets, where it was held by silk. The spider then climbed back to the web base and pressed the gnaphosid against the base sheet, where it remained attached. The spider then went back to the attack site and began repairing the web.

Prey. I collected 40 different prey remains from $H$. thorelli webs. Insect families represented were Tipulidae (8), Formicidae (4), Gryllacrididae (2), Ptilodactylidae, Cerambycidae, Lampyridae, and Cicadellidae (one each). Nine specimens could only be identified to order: Diptera (6), Coleoptera, Trichoptera, Lepidoptera (one each). Other arthropods included 9 opilionids and 4 spiders (one gnaphosid, one lycosid, one Hypochilus, and one Antrodiaetus.)

The most common prey, opilionids (daddy-longlegs) and tipulids (crane flies), are extremely abundant in the situations in which $H$. thorelli constructs its webs. Ants (Formicidae) are also common on rock faces. Cave crickets (Gryllacrididae) are also abundant, but are apparently usually able to avoid $H$. thorelli webs. At Wolf Creek, I observed a number of cave crickets leaving a deep crevice, at the mouth of which was a large Hypochilus web. The long antennae of the cave crickets enabled them to detect the web before they could become entangled.

The single case of cannibalism occurred with captive specimens. One female left her box compartment before building a web and wandered into the adjacent compartment containing a female that 
had already built a web. The remains of the first female were directly under the other's web, but there was no evidence of damage to the web, so I do not know if the first female became entangled or was attacked on the guy lines.

Web function. The circular sheet of silk laid down on the substrate serves as an attachment point for the lampshade, and provides an anchor point for the spider's last pair of legs during prey capture. The lampshade, containing sticky cribellate silk, is the actual prey trap. In addition, the lampshade serves as a protective retreat for the spider.

The support and frame lines in $H$. thorelli webs function chiefly in support of the lampshade. They are too far apart to form an efficient prey trap, but may help deflect flying insects into the lampshade. These lines also serve to signal the approach of a potential predator (see Defensive Behavior below). The tangle of threads serves to support and anchor the lampshade. A secondary function of the tangle is to warn of potential predators. Although prey do become briefly caught in the tangle, $H$. thorelli does not attack them there.

The web of Hypochilus is not as efficient as a two-dimensional orb web (in terms of effective area covered per quantity of silk), but it has the advantage over such strictly aerial or other strictly ground webs of being able to capture both crawling and flying arthropods. The two most abundant prey (see above) were tipulids (flying arthropods) and opilionids (crawling ones). Crawling arthropods - ants, daddy-longlegs, cave crickets, and spiders - comprised $47.5 \%$ of the 40 prey remains I collected. These ground arthropods probably encounter the base of the lampshade while crawling on the rock surface. The flaring of the lampshade enables it to capture these prey when they struggle and fall after contacting the lampshade base. Thus the lampshade is able to intercept movements that are either perpendicular to the substrate or parallel to it.

Since it builds an aerial web and does not use silk either to overcome or secure prey, Shear (1970) placed Hypochilus between steps 2 and 3 in the scheme of spider prey-capture evolution proposed by Eberhard (1967):

I. No web is spun, prey subdued by biting.

2. Ground web spun, prey subdued by biting.

3. Aerial web spun, prey subdued by biting and wrapped to prevent loss during subsequent attacks.

4. Aerial web spun, prey subdued by biting and wrapping.

5. Aerial web spun, prey subdued by wrapping only. 
My own observations indicate that Hypochilus may be placed somewhat closer to step 2, since its web, both in placement (on rock ledges) and in function (capturing ground and aerial arthropods in nearly equal numbers), is neither strictly a ground nor strictly an aerial web. Kaston (1964) hypothesized that early snares arose from a fringe of drag lines radiating from the mouth of a silk-lined retreat. Shear (1970) proposed that "the web of Hypochilus can easily be derived" from such a structure, and suggested that the lampshade may represent an extension of the original retreat, while the paired support lines may represent the capture (originally drag) lines in Kaston's scheme.

\section{Defensive Behavior}

The defensive behavior of $H$. thorelli is very similar to that described by Shear (1970) for $H$. gertschi. There are three major components to the defensive behavior: "vibrating," "running," and "death-feigning"; and one minor component, "crouching." The vibrating response is elicited by a mild disturbance of the frame and support lines. The spider reacts by oscillating its body rapidly in a plane perpendicular to the substrate surface.

Disturbance of the mesh of the lampshade may trigger one or more of the other three responses. The "crouching" response is one in which the disturbed spider withdraws to one side of the web base and huddles there. Usually, if the disturbance is continued, this is followed by the "running" response, in which the spider cuts through the lampshade with its chelicerae and runs along the substrate. The spider may instead scramble over the mouth of the lampshade, and then run along the substrate. Rarely, the spider cannot be provoked into any action other than "crouching."

Touching the spider or suddenly disturbing the mesh often results in the spider's leaping suddenly out of the web. Leaping (rather than simply dropping) enables spiders in webs on vertical rock faces to clear the edge of the lampshade. Upon striking the ground, the spider assumes the folded position shown in Figure 5. Spiders in this position are very difficult to see in the ground cover beneath the web. They remain in the "death-feigning" position for 5 to I 5 minutes, then climb back up the substrate until they encounter either the tangled portion of the web or the web base. This procedure usually presents no particular difficulty, as the spiders are directly under the web when they land. No dragline is spun when the spiders leave their webs by running or leaping. Probably gravitational cues are used in orientation, at least until silk is encountered. 


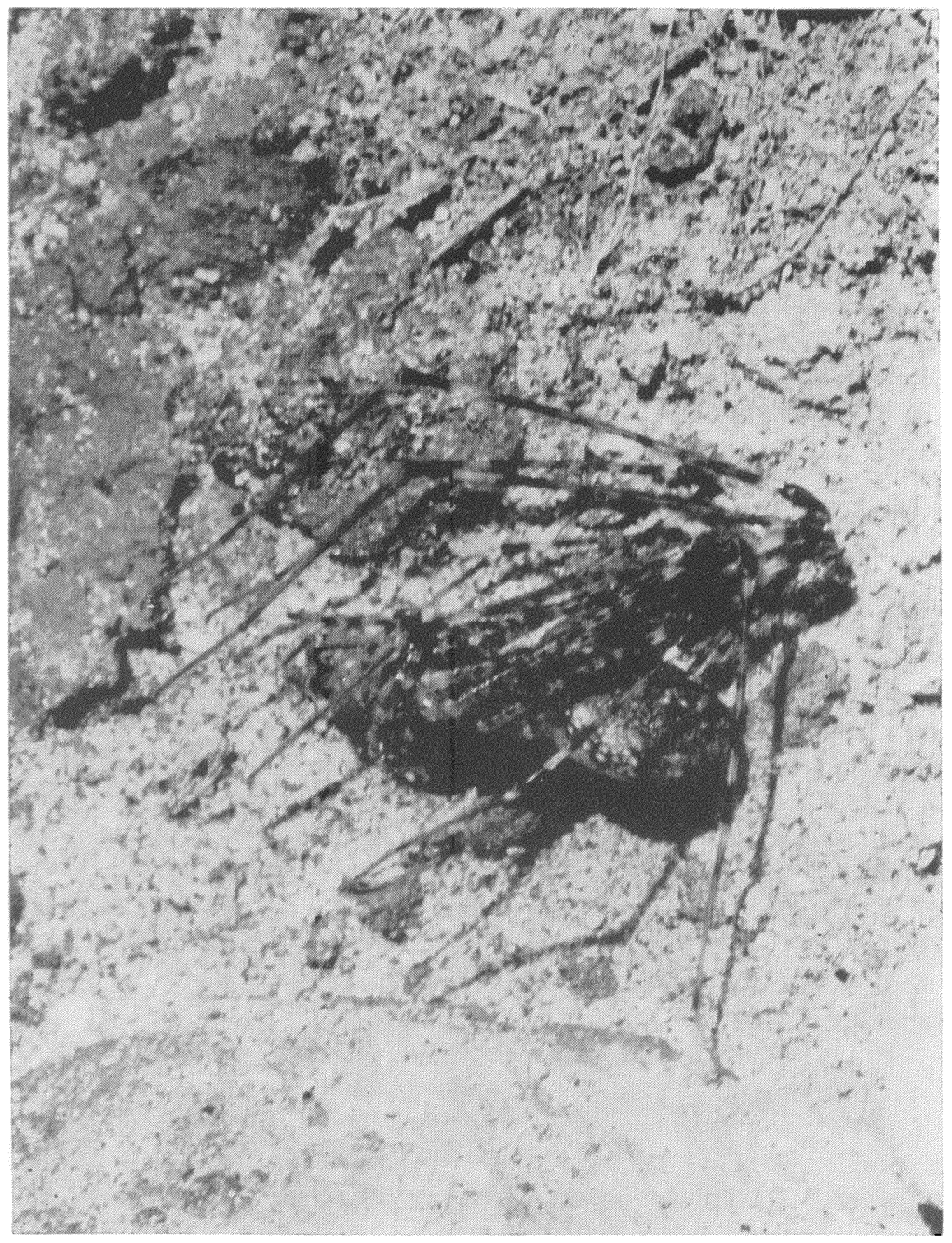

Figure 5. Mature female of $H$. thorelli in "death-feigning" position. The legs of this specimen are less tightly flexed than usual, since the spider had to be moved in order to obtain the photo. Photo by L. Tucker. 
Mature males, when disturbed, either run or flatten themselves against the substrate, but none were observed to "feign death."

The function of the vibrating response is unclear. It does not resemble the "testing" of web tension, which is accomplished in a different manner (see Predatory Behavior above). It may aid in camouflage by blurring the visual image received by a predator. Vibrating may function in dispersing a defensive chemical, as it does for some opilionids, or it may be mimicry of such behavior.

Another important defensive mechanism is the cryptic coloration of Hypochilus (Figure 4), which allows it to blend in remarkably well with rock surfaces when in its usual resting position.

$H$. thorelli does not display autotomy, a common defensive mechanism among most other spiders.

\section{Reproductive Biology}

Morphological and behavioral changes. Males mature early in August. (I collected the first mature specimen on 5 August; they became abundant soon after then until October, and the last one was observed on 7 November.) The males undergo their final molt in a molting web. This web has a circular base of about the same size as the base of the usual web, but the sides of the web extend away from the substrate for about $12-15 \mathrm{~cm}$, tapering to a mouth somewhat smaller than the base. The mouth is sealed off with a loose network of silk. Whether they alter their old webs or move to new locations to build the molting web is unknown. The molting web probably offers greater protection from predators during the (presumably) more difficult final molt. W. A. Shear (pers. comm.) reports that the same type of web is constructed by males of $H$. gertschi.

Sexually mature males are strikingly different in appearance from immature specimens and females. In addition to other morphological changes, they develop relatively longer legs (Figure 6) in the final molt and the legs change in color from pale yellow and brown to dark reddish-brown. The greater length of the legs of the males is related to their use as tactile organs during courtship behavior (see below), and may also improve locomotion during their search for females (see also below). The reddish-brown coloration is a result of heavier cuticular sclerotization, which lends greater strength to the elongate appendages. The color is not as cryptic as is the normal coloration.

Several changes in behavior occur with the final molt (see also Defensive Behavior above). The males cease feeding, let their webs 


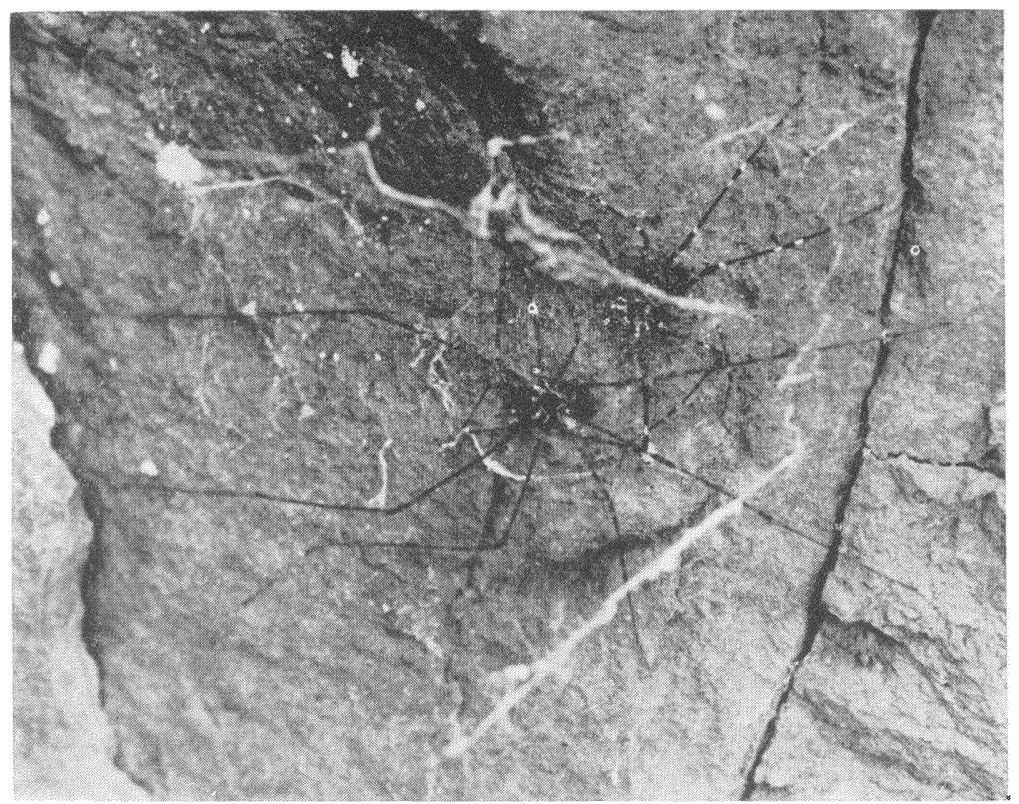

Figure 6. Mature male and female of $H$. thorelli. Note the greater leg length of the male (on left). Photo by L. Tucker.

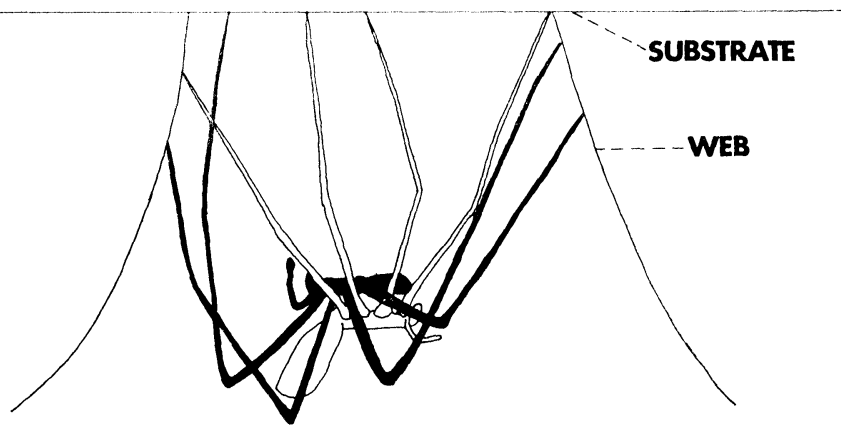

Figure 7. Mating position of $H$. thorelli. Male black, female in outline. Drawn from field sketch. 
degenerate, and wander in search of females. Most of the wandering is nocturnal, and the males are usually inactive during the daylight, often resting within the circular base of an abandoned web.

Females do not undergo a drastic physical metamorphosis during their final molt, and they continue to carry on their normal predatory and defensive behavior patterns.

Courtship and mating. In all i9 observations of courtship behavior, wandering males were seen to use their first pair of legs as "feelers," often waving them about when advancing along a rock surface. When a male makes contact with silk, he stops immediately with one or both first legs touching the silk. (No males were seen to contact any silk but that of Hypochilus webs; what their reaction is to other webs is unknown.) After a brief pause, he strokes the web with one first leg. The stroke may be either a "tapping" of the silk, or a plucking motion wherein he extends his leg over the silk, then draws it across the silk back toward his body. If this precipitates an attack by the female, he backs rapidly away for 8 to $15 \mathrm{~cm}$. If no rush occurs (usually the case when the male has contacted the guy lines of the web), the male proceeds a little farther and strokes the silk again. If by this time he has reached the support lines or the mesh of the lampshade, his stroke will cause a rush by the female and he backs away, returning again after a pause of from 30 seconds to well over an hour. This sequence may go on for some time, usually ending with the male's leaving in search of another female. One such encounter observed went on for 3 hours, after which time the male left.

The female usually exhibits a normal predatory response at first. After several fruitless rushes, however, the female may scramble out of the lampshade and onto the guy lines in pursuit of the male. (No females were seen to actually capture any males.) One female did not show any response at all to a male that held on to the lampshade for I.5 hours. This male had stroked the web only once.

One female attacked five times in 25 minutes, but stopped and allowed the male to enter her web. He remained there for I hour, during which time they approached very closely. Both "tapped" frequently, often striking one another. This encounter did not result in copulation; the male abruptly left with no apparent threat by the female.

Mating behavior was observed once (13 September 1970), with captive specimens. The male contacted the female's web Io minutes after he was introduced to the box (at 6:58 PM), and plucked the web. The female gave no apparent reaction, and the male suddenly 
scrambled into the lampshade. The female positioned her legs so that they held her away from the substrate, with her abdomen inclined away from, and her cephalothorax parallel to, the substrate (Figure 7). The male approached from the front and maneuvered between the substrate and the female's cephalothorax, so that the dorsal side of his abdomen was in close proximity to the ventral side of her cephalothorax. The pair was turned in such a way that it was not possible to see the manner of insertion of the pedipalps. After 3 minutes, the male disengaged, but remained in the web. Both remained in crouching positions inside the web until the end of the observation 2.5 hours later. I cannot definitely say whether or not sperm transfer took place, as the female died a week later without depositing eggs.

Since the single observed case of mating took place with such apparent ease, it may be that the other cases observed involved females that had already mated and were not receptive. The female observed mating had been captured on 7 August and may not have had an opportunity to mate.

Visual signals are not important in courtship behavior. Web vibrations are the only obvious signals employed. Pheromones may possibly be released by receptive females upon receiving tactile signals from the males.

Courtship and mating patterns are those that are to be expected of a sedentary species with poor vision. Courtship is generalized, involving no elaborate displays on the part of the male, who alerts the female by simply pulling on the web. The mating position assumed is the "Dysdera embrace" common to web-building araneomorphs (Gertsch, 1949).

Oviposition. Eggs are deposited several weeks after mating. (I found the first egg sac on 9 September.) The eggs are surrounded by a slightly flattened sac of tough, opaque silk about 6 to $8 \mathrm{~mm}$ by 4 to $5 \mathrm{~mm}$, with a continuous seam dividing it into two halves along the long axis. Covering the opaque silk is a layer of finely meshed silk, in which are embedded bits of wood, leaves, moss, small flakes of stone, and lichens so that the white sac itself is scarcely visible (Figure 8 ). The entire sac is suspended at one end by one or two thick strands of silk and several fine strands so that it dangles from the rock surface, or it is held fairly securely to the rock surface by a number of strands attached at several different points. The covering of the sac usually matches the adjacent rock surface. At Dry Falls, I observed two sacs one foot apart. One of these was on a section of rock covered with moss; the sac was covered primarily with moss. The other 


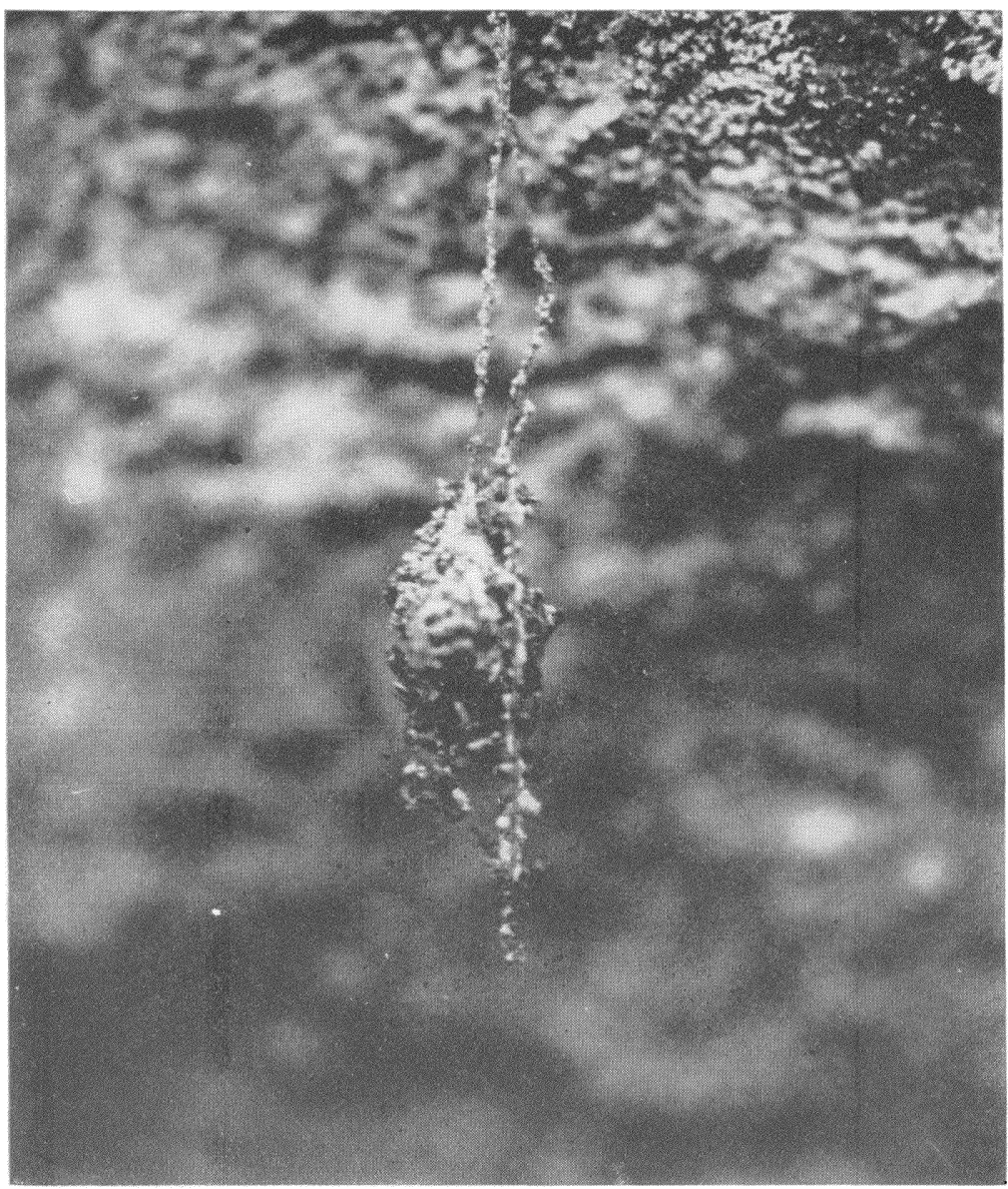

Figure 8. Egg sac of $H$. thorelli. Note covering of egg sac and the two suspending threads. 
sac was on a section of rock covered with gray lichens; this sac was covered with gray lichens. No covering is put on the sac when it is attached to a bare rock or one covered with white crustose lichens. The sacs are attached some distance away from any webs, though in the same microhabitats, and the females do not guard them after they are completed.

I have records (field notes) for 48 single egg cases, 12 records of 2 cases attached together, and I record of 3 together. Not all of these were collected, however, so I have records of egg numbers for only I pair (50 and IO3 eggs) and for the single instance of 3 sacs attached together (45, 8I, and 92 eggs). The mean for 25 single egg sacs examined was 74.4 eggs; range 3I-IO9. Eggs are whitish and spherical, measuring about I.IO $\mathrm{mm}$ in diameter (mean of 25 eggs measured after 2 days in $80 \%$ ethanol; range I.07-1.15 mm).

I was unable to determine the number of egg sacs constructed per female. Presumably when two cases are attached at the same place on the rock face, they were deposited by the same female. Females were observed with incomplete egg cases (lacking camouflage) on 9 September, 28 October, 21 and 22 November. In all instances the cases were sealed up and attached by a single strand.

\section{Life History}

Postembryonic development. Egg sacs are deposited from September through November. The winter is spent in the egg stage, with eclosion occurring in the spring. One sac containing "prelarvae" (see below) was collected on 6 March (elev. $700 \mathrm{~m}$ ), but until 20 April, all others collected still contained only eggs. Twelve sacs were collected on 27 April in the Nantahala Gorge (elev. $600 \mathrm{~m}$ ); all of these still contained eggs.

In $H$. thorelli, there appear to be five instars between eclosion and dispersal from the egg sac. (I determined these by examination of preserved egg sacs collected from March through May.) After the terminology of Vachon (1957), there are two prelarvae, one larva, one prenymph, and one nymph. The nymph is the active stage (about $2 \mathrm{~mm}$ in total length) that emerges from the egg sac and constructs a web. Hereafter nymphal stadia will be referred to as spiderlings.

Dispersal and first web. Spiderlings were first found out of the egg sac on 25 May. Many of these were still within the opened egg sac. Those that were out of the sac were on the adjacent rock face. Silk was present where the spiderlings had gathered, but no definite webs were visible. The sac involved had been marked on 

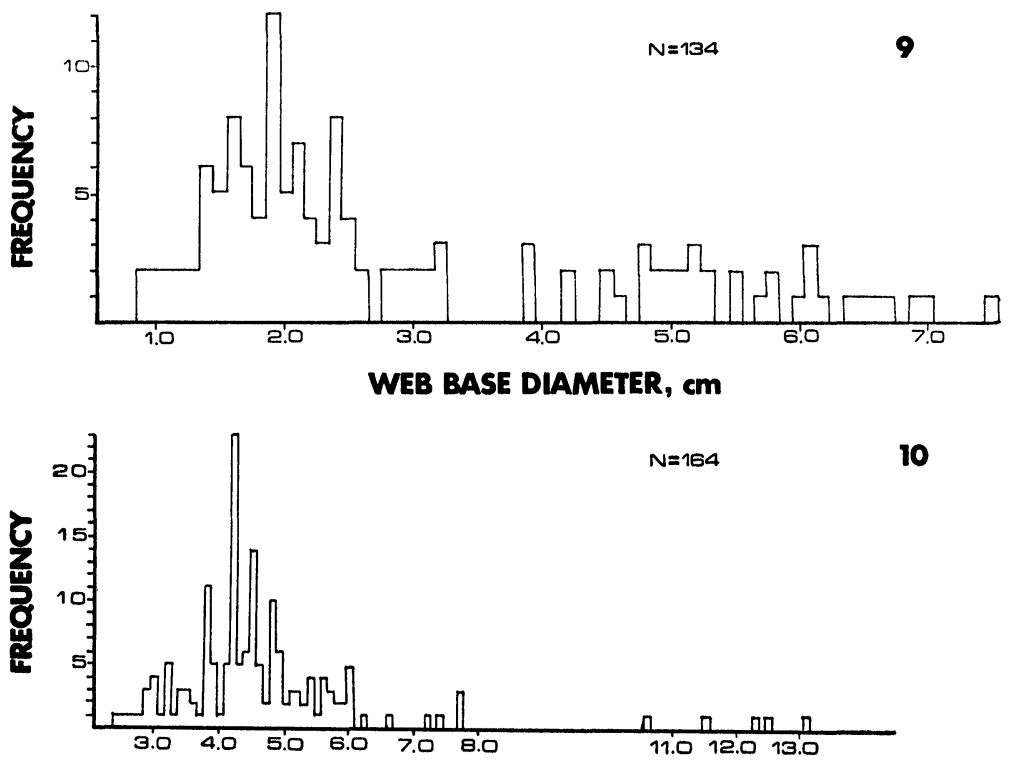

TIBIA I LENGTH, $\mathrm{mm}$

Figure 9. Base diameters of 134 webs of $H$. thorelli. Explanation in text.

Figure 10. Length of the tibia of the first leg of $H$. thorelli, 164 specimens. Explanation in text. 
27 October. This sac, like all others observed (including those left over from previous years), had been opened at the top.

The spiderlings probably disperse from the sac simply by scattering out over the substrate. The small first web is similar to that built by adult spiders, though the tangle appears to be relatively less extensive than in the adult webs, and resembles a flat sheet more than a three-dimensional tangle. The lampshade portion of the web appears to be shallower than in adult webs. The spiderlings assume the same resting position as adult spiders.

Life cycle. After constructing webs, the spiderlings begin feeding, and grow until fall. I did not determine the number of molts involved. They do not attain sexual maturity during the August following eclosion. They apparently spend the winter in crevices in the rock substrate. (I found one at Mull Creek in March by pulling large loose rock flakes off an overhang.) These spiders appear again in the spring. The first ones were found I4 March at Whitewater Falls and I5 March at Wolf Creek. By early May all the overwintering spiders are again active. They then grow and reach sexual maturity in August (see Reproductive Biology). All males die during the fall; a few females survive until the following spring. (I found thre active adult females during April and May.)

Data for the length of the life cycle were obtained by measuring the sizes of webs and by measuring the sizes of the spiders. On the assumption that the size of the web base is proportional to the size of the spider (which sits with its legs radiating out to touch the sides of the web base), and that the size of the spider is proportional to its age, I measured web base diameter of I34 webs (Figure 9) of $H$. thorelli during August and September, 1970. (The length of time involved may have introduced some bias into the results.) Figure 9 shows that there are two classes of web size, with a break between 3.2 and $3.8 \mathrm{~cm}$. This suggests that there are two age classes of spiders during late summer: those that had hatched the previous spring, and those that are of reproductive age.

For another sample of spiders, I measured the length of the tibia of the first leg to determine size classes. Carapace width or length were not discrete enough to measure reliably. Collections of spiders for measurement were made from 23 October until I November. Because two broad groups were in evidence at the time - large, actively reproducing spiders and smaller, non-reproducing ones - an attempt was made to collect only a large number of smaller ones to determine the number of years required to reach sexual maturity. However, five adults were collected during that time period. Fig- 
ure Io shows the results obtained. The values of $10.8 \mathrm{~mm}$ and larger represent the adult (sexually mature) female spiders. The distribution characteristics of the values from $2.4-7.7 \mathrm{~mm}$ show that only one age class of non-reproductive spiders is present; i.e. the pre-reproductive period lasts for about two years (from egg to maturity). I performed a skewness test on the distribution which verified that it represents a sample from a normally-distributed population ( $P$ 0.95). This agrees with the above data obtained from measuring web base diameters. Figure ro does not indicate the length of the life cycle following sexual maturity. However, because I found no extremely large spiders during the fall, and because of the web base measurements (which were not recorded selectively), I feel that individuals of $H$. thorelli reproduce for only one year, with perhaps a very small proportion of females reproducing for a second year.

Although no other papers on hypochilomorph life history have been published, one would expect these primitive spiders to have, like $H$. thorelli, life cycles of more than one year. All mygalomorphs have life cycles of several years, and a few of the more primitive araneomorphs (some segestriids, scytodids, and filistatids) live for more than one year (Gertsch, 1949). Although some higher araneomorphs such as an araneid, some lycosids, and a pisaurid (Dondale, i96I) require two years to reach sexual maturity, most live for only a single year.

\section{Conclusions}

Although a member of taxa which are phylogenetically and geographically relict, Hypochilus thorelli is surprisingly abundant. Its success can be attributed in part to the relative abundance of its specialized habitat within the southern Appalachians, and to its generalized prey-capture mechanism.

The hypochilomorph spiders are, on morphological evidence, considered essentially intermediate between the mygalomorphs and araneomorphs. This conclusion is also supported by some of the behavorial and life history characteristics of $H$. thorelli. Its web is more advanced than any such structure among the mygalomorphs; its method of subduing prey by simply biting it to death is also primitive. Its life cycle is longer than that of most araneomorphs, yet is not as long as that of most mygalomorphs.

\section{Acknowledgements}

I must express my appreciation for the advice, discussions, and 
understanding of my advisor, Dr. Frederick Coyle. Drs. Allen Moore and J. Dan Pittillo provided many suggestions for improvement of the thesis, and Larry Tucker helped with the photography.

\section{Comstock, J. H.}

\section{Literature Cited}

1940. The Spider Book, revised and edited by W. J. Gertsch. Comstock Publishing Co., Ithaca, N. Y. 729 pp.

Dondale, C. D.

1961. Life histories of some common spiders from trees and shrubs Eberhard, W. in Nova Scotia. Can. J. Zool. 39 : 777-787.

1967. Attack behavior of Diguetid spiders and the origin of prey wrapping in spiders. Psyche 74: 173-181.

GerTsch, W. J.

1949. American Spiders. D. Van Nostrand Co., Inc., Princeton, N. J. $285 \mathrm{pp}$.

1958. The spider family Hypochilidae. Amer. Mus. Nov. 1992: 1-28.

HoFFMAN, R. L.

1963. A second species of the spider genus Hypochilus from eastern

KASTON, B. J. North America. Amer. Mus. Nov. 2148 : 1-8.

1948. Spiders of Connecticut. Hartford, Conn. $874 \mathrm{pp}$.

1964. The evolution of spider webs. Am. Zool. 4: 191-207.

KraUs, 0 .

1965. Hypochilus, ein "lebendes Fossil" unter den Spinnen. Nat. und

Marples, B. J. Mus. 95 : 150-162.

1968. The hypochilomorph spiders. Proc. Linn. Soc. London 179: 1131.

Petrunkevitch, A.

1932. Collecting Hypochilus. Jour. N. Y. Ent. Soc. 40: 19-23.

SHEAR, W. A.

1970 (1969). Observations on the predatory behavior of the spider Hypochilus gertschi Hoffman (Hypochilidae). Psyche 76: 407417.

VACHON, M.

1957. Contribution a l'etude du developpement postembryonnaire des araignees. Premier note. Generalites et nomenclature des stades. Bul. Soc. Zool. France 82 : 337-354. 

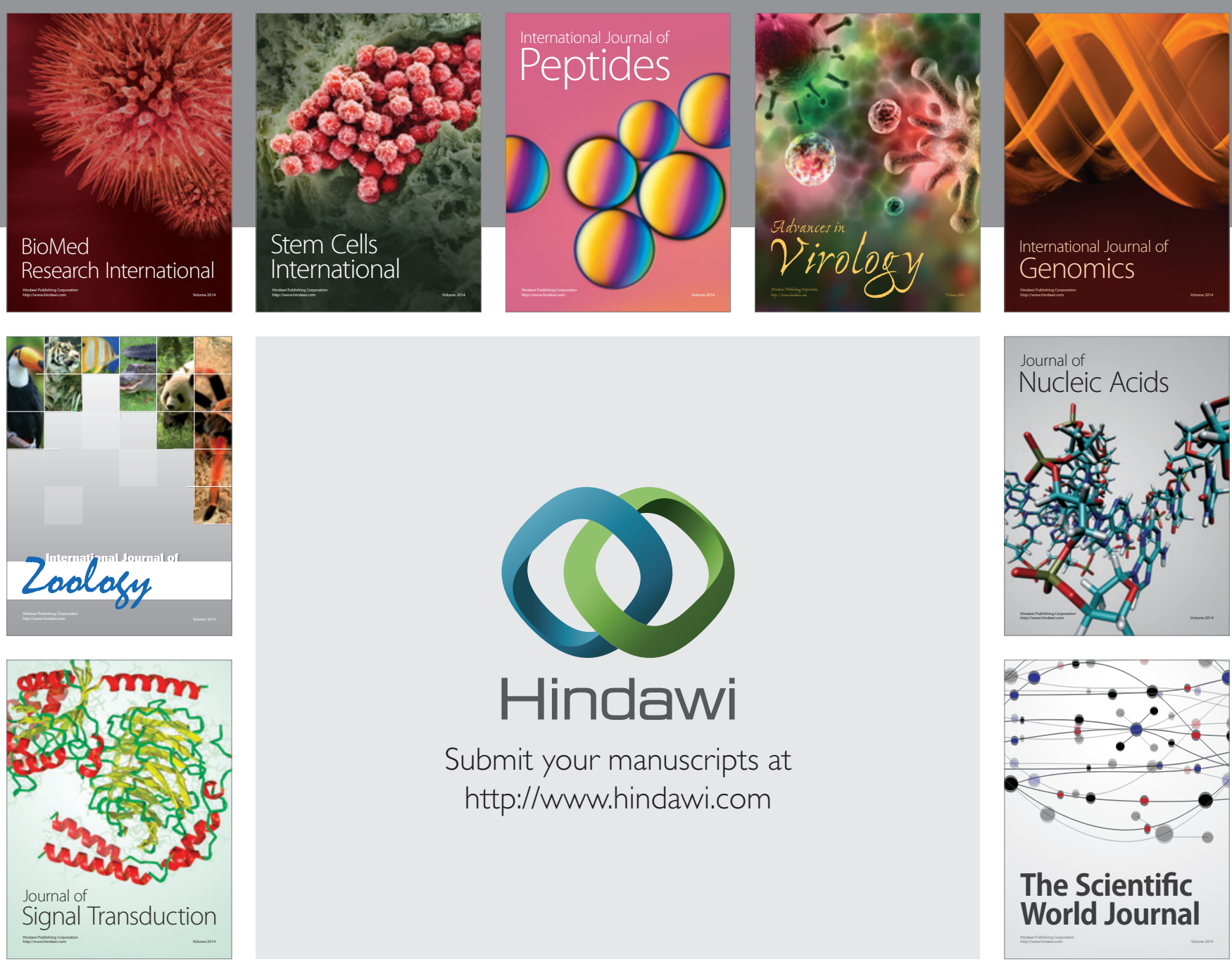

Submit your manuscripts at

http://www.hindawi.com
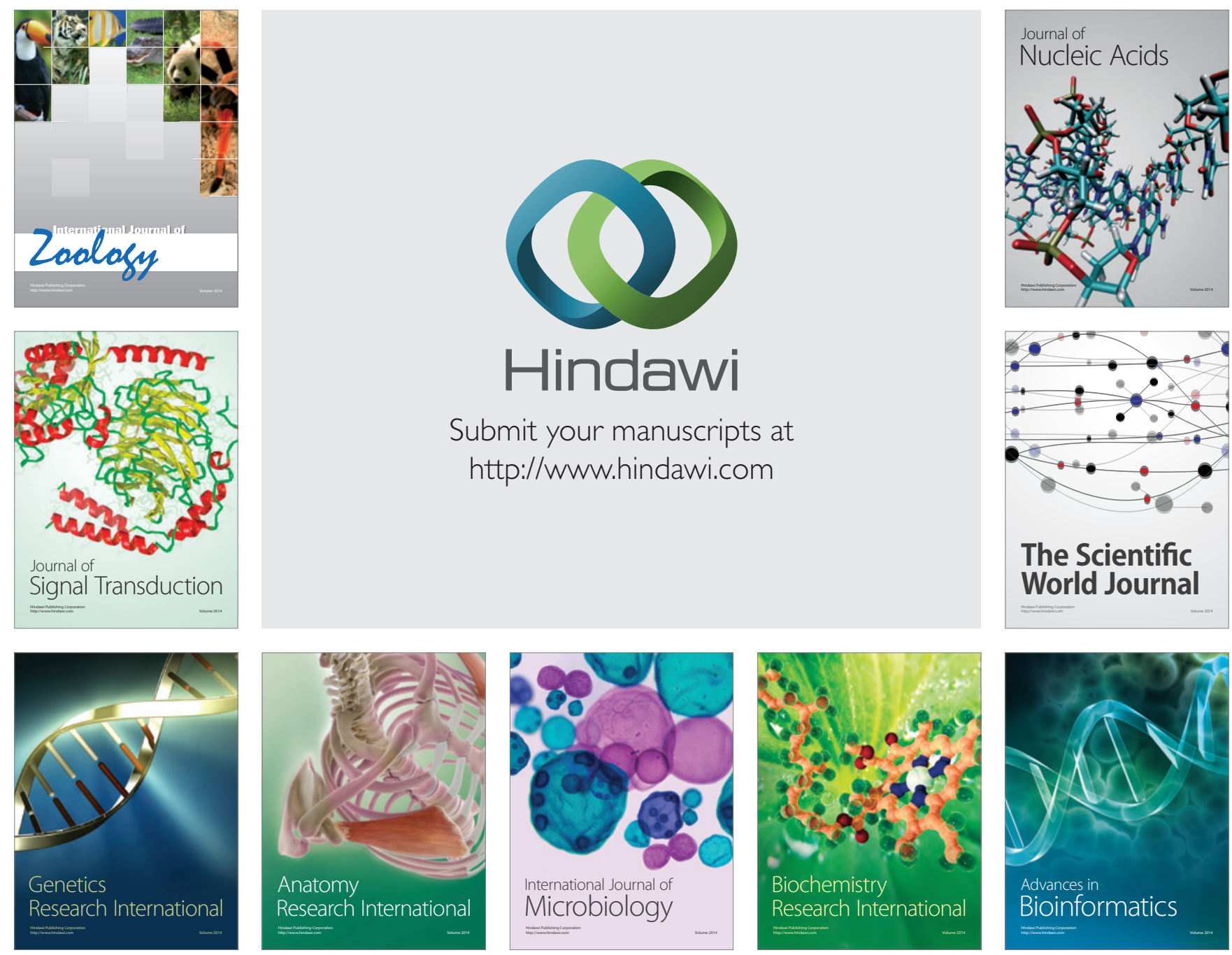

The Scientific World Journal
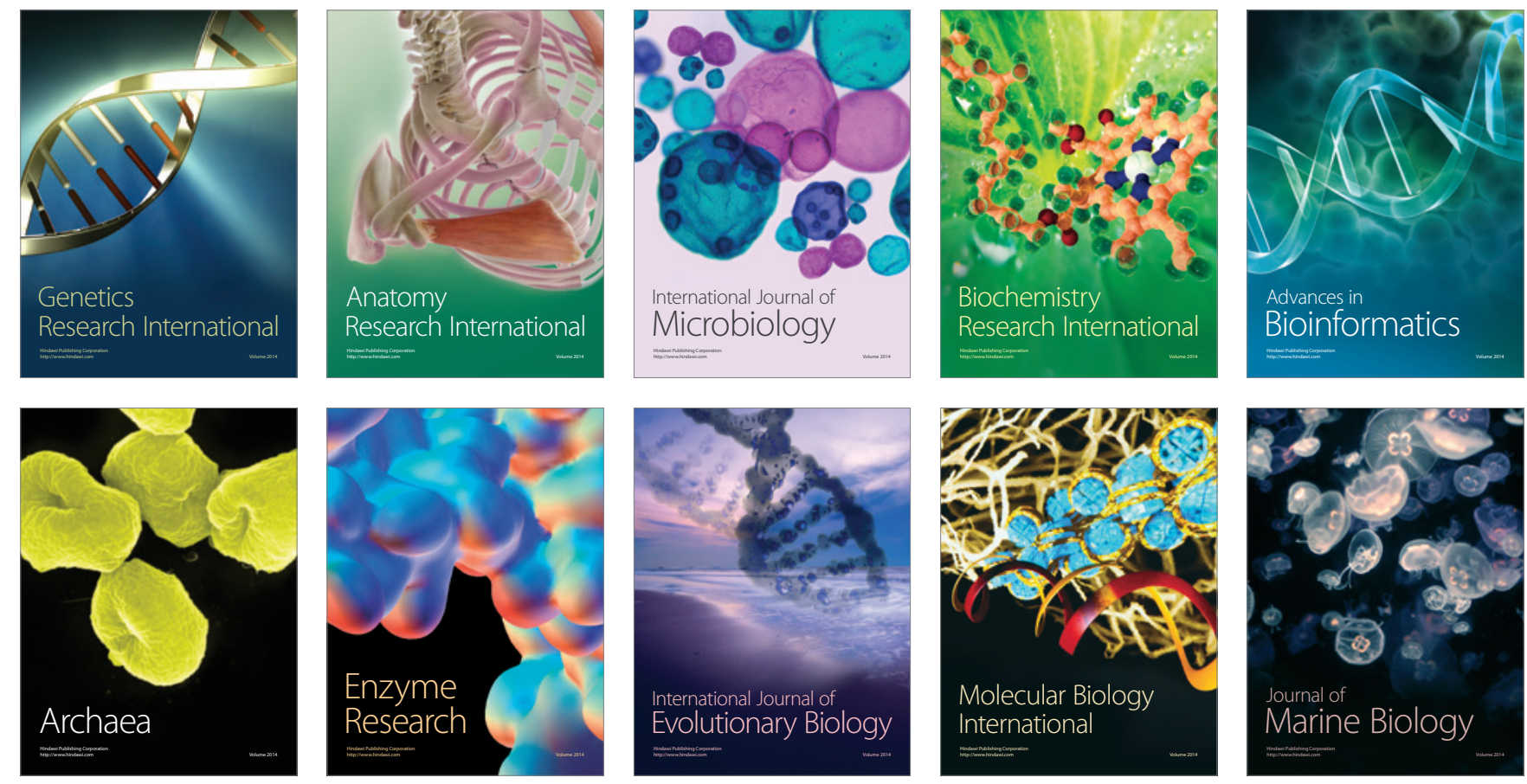